\title{
The best interests of the child: More questions about this construct?
}

\author{
Frank Ainsworth, James Cook University, Townsville, Australia
}

\begin{abstract}
In this article I examine the best interests of the child construct and raise questions about the utility of the construct. I also draw attention to Winnicott's good enough parenting proposal as an alternative conceptualisation that addresses the issue of parental child-rearing capacity.

The best interests construct that emanates from the US has been the dominant international child-protection paradigm for at least two decades. Associated with this construct is a focus on individual parental pathology and child-rearing deficits. Yet, family poverty is the dominant factor, rather than parental pathology or incapacity, that precipitates many child abuse and neglect cases. The question is, has the best interests construct, one that ignores poverty and social disadvantage, outlived its usefulness? This construct has certainly affected Aboriginal families and led, as evidence shows, to the over-removal of children from these families. A range of alternative interventions and a social model of child protection is then canvassed.
\end{abstract}

\section{Introduction}

Since the publication of Beyond the Best Interests of the Child (Goldstein et al., 1973) and Before the Best Interests of the Child (Goldstein et al., 1979), plus In the Best Interests of the Child (Goldstein et al., 1986) and finally, The Best Interests of the Child. The Least Detrimental Alternative (Goldstein et al., 1996), international child protection legislation and casework practice has been shaped by this construct. A cross-national analysis of child welfare decisions in relation to child removals supports this view (Burns et al., 2017). In 2009 and 2011, two publications (Hansen \& Ainsworth, 2009, 2011) raised questions about the construct, the best interests of the child. This article again takes up this theme.

\section{AOTEAROA}

NEW ZEALAND SOCIAL WORK 33(2), 104-113.

CORRESPONDENCE TO: Frank Ainsworth frankainsworth@hotmail.com

\section{An alternative conceptualisation}

A powerful, alternative conceptualisation and a challenge to the best interests of the child construct is Winnicott's good enough parenting proposal (Winnicott, 1973). One reason for this is that the good enough parenting idea is less dependent on legalistic thinking and it is firmly rooted in knowledge about child and family development. The phrase good enough parent was first used by Bettelheim (1987), before the Goldstein et al. (1973) best interests construct that is steeped in Freudian psychoanalytic theory, began to dominate child protection practice.

The Winnicott proposal, that is also influenced by Freudian theory, takes us away from the legalistic best interest construct about which there is no agreed definition, in child protection law or science (Hansen \& Ainsworth, 2009). Central to the position put forward in this article is Winnicott's prime focus on the parent-child (especially the mother) relationship as the foundation of a child's healthy growth into adulthood (Winnicott, 1960). This theory does not separate the child from the parent, as does the best interests construct with its singular focus on the child's alleged best interests at the expense of all else 
(Featherstone et al., 2018), resulting in what these authors label as:

[An] "atomised" child, severed from family, relationships and social circumstances: a precarious object of "prevention" or rescue. (Featherstone et al., 2018, p. 27)

In that respect, the best interests construct is best characterised as social aspiration (Spinak, 2007). The Winnicott proposal is also more amenable to the creation of guidelines for use by practitioners, the absence of which makes for a resort to rule-of-thumb decision making by child protection and legal personnel (Kahneman, 2011). It is also likely to be more comprehensible to parents who are involved with child protection services.

The further advantage of the good enough parenting idea is that is keeps the focus on parents and their parenting capacity-which is at the centre of child protection concerns. It does not solely focus on the child. The sole focus on the child separates the interests of the child from those of the parents, when it can be argued that these interests are inextricably linked (Guggenheim, 2007).

It is potentially enlightening to consider why the best interests of the child construct has been so widely accepted and why the good enough parenting proposition did not gain ascendancy as a concept to guide legislation and policy. The following points have a bearing on this in my view. The first is that, for children's rights advocates, Winnicott's proposal is too sympathetic to parents. The second is that children's rights activists, including many lawyers, were sympathetic to the best interests construct as it was, in the main, authored by lawyers. Thirdly, it can be argued when it comes to child protection legislation, lawyers are in the best place to influence the drafting process. The best interests construct is not embedded in knowledge about child and family development. Social workers and psychologists, working in child protection services generally have a wider grasp of this knowledge, and in an earlier era before the best interests construct (Goldstein et al., 1973), the Winnicott good enough parenting proposal was favoured. Indeed, while not a faculty member, Winnicott taught child development to students on the London School of Economics social work qualifying course at least between 1968 and 1969 (I was one of his students). However, social workers and psychologists do not have the same influence as lawyers in the law-making process and those drafting the relevant legislation may not have been aware of Winnicott's good enough parenting proposal. Finally, Winnicott did not have as strong an affiliation with a distinguished university as Goldstein, Freud and Solnit did. I will argue here that it is time to move on from the historical conjunction that enabled the adoption of the best interests of the child construct and to establish principles which promote a more equitable family and child well-being system (Dreyfus, 2020).

\section{Differential community values}

The Goldstein texts are shaped by US values as they are products of Yale Law School, and the Yale Child Study Centre. The individualistic focus of the best interests construct was also enhanced by Anna Freud's child development knowledge derived from her British clinical practice. Winnicott's good enough parenting proposal is drawn from an identical British clinical base but, as can be seen, the outcome is different. The explanation for this may be that Winnicott wrote independently and stayed within his knowledge base. On the other hand, Freud lent her knowledge to children right's lawyers who may have diluted her input.

Importantly, the Goldstein texts and the best interests construct that they promote are not value free. Indeed, Dallek (2018) the biographer of Franklin D. Roosevelt cites David Kennedy who pointed out that, in the US, in the 1930s:

The Depression ... revealed one of the perverse implication of American 
society's vaunted celebration of individualism. In a culture that ascribes all success to individual striving, it seemed to follow automatically that failure was due to individual inadequacy. (Dallek, 2018, p. 153)

The recent Trump presidency confirmed that this value position remains a central feature of American culture. Regardless of this, over time there has been little criticism or reworking of the best interests construct to account for cultural variations and the vastly altered social circumstances of families since the original publications. Nor has there been an examination of the way US social and political values (and the associated commitment to individualism) has influenced the best interests construct. In concert with the emphasis on individualised rights, a focus on parental psychopathology is embedded alongside the best interests construct. This thinking has influenced the development of clinical programmes such as Multi-Systemic Therapy, Child Abuse and Neglect (MST-CAN) ${ }^{\circledR}$ and Family Functional Therapy, Child Welfare (FFT-CW) ${ }^{\circledR}$, that seek to change aspects of parental behaviour. The programmes essentially locate causation individually and do not take account of social factors.

What is remarkable is that the best interests of the child construct has been embraced by child protection legislators and practitioners from countries that have a commitment to a set of social values significantly different from the US. Britain, Australia and Aotearoa New Zealand for example, have generally subscribed to policy frameworks with a stronger social and community centred perspective (Everson, 2016a, 2016b; Forbes, 2019). The argument put forward in this article is that this construct consequently needs to be re-examined both because of its 46-year history and because of the cultural context of countries like Britain, Australia and Aotearoa New Zealand, where there is a commitment to a different set of social values from the US. There is of course, an increasingly vocal lobby in the
US that seeks to change these social values. This drive is epitomised by the passing into federal legislation of the hard-fought Patient Protection and Affordable Care Act 2010, colloquially known as Obamacare, and described as socialist by its Republican opponents.

\section{Poverty and social disadvantage}

The next section of this commentary focuses on a range of social factors that have a significant bearing on the incidence of child abuse and neglect (CAN). A recent Australian study reinforces this position, and I quote:

We estimate that $27 \%$ of all child maltreatment was jointly attributable to economic factors. These findings suggest that strategies that reduce economic disadvantage are likely to hold significant potential to reduce the prevalence of child maltreatment.

(Doidge et al., 2017, p. 14)

This quotation confirms that poverty/ economic disadvantage is a major influence on the incidence of CAN. Other research from the US provides evidence of the impact of economic inequality as a factor that has a significant influence on CAN (Eckenrode et al., 2014). From England, the Rowntree Foundation report, "The relationship between poverty, child abuse and neglect" (Bywaters et al., 2016) reaches a similar conclusion. Further confirmation is to be found in a later, UK four-nations study of child welfare inequalities (Bywaters et al., 2018). Given this evidence, some scholars are beginning to argue that there is a causal link between low income and child maltreatment, not just a correlation as is often stated (Cancian et al., 2013; Institute for Research on Poverty, 2017; Doidge et al., 2017). There is also much earlier evidence that underlines how living in an area of social disadvantage produces significant misery and depression and is undermining of good parenting (Ghate \& Hazel, 2002). Furthermore, it is well established that child protection authorities 
engage in stricter surveillance of poor neighbourhoods and communities (Cocks, 2018).

Given that US and English studies underline poverty and social disadvantage as crucial factors in cases of CAN, these factors need to be examined before overly simple judgments are made about parenting capacity. It may be that these factors offer a better explanation for CAN and show why some parents, when under stress, abuse or neglect their children. In these circumstances, individual treatment interventions, resulting from an adherence to the best interests construct, can be viewed as inappropriate and misused, or at least as an incomplete explanation and response to CAN.

The work of Krumer-Nevo (2020) on poverty-aware practice for social work, coupled with that of Saar-Heiman and Gupta (2019) in relation to child protection that is based on the view that poverty is a violation of human rights and thereby a breach of social justice, further underlines the issue of poverty and CAN.

\section{Disadvantaged communities}

There are several epidemiological studies that look at the geographical distribution of CAN cases. A study in Hong Kong identified the neighbourhoods that generate the most cases of CAN. The neighbourhoods were distinguished by high levels of public housing and the low socio-economic status of residents (Government of Hong Kong, 2013). A similar study in Fort Worth that used a terrain-mapping methodology to predict CAN also found that geographic locations characterised as socially disadvantaged and with high levels of poverty were the places that generated the most CAN cases (Daly et al., 2016). An older study of the geographic distribution of child abuse cases in an inner London borough reports similar findings and suggests that the areas identified as generating a high level of CAN cases should be targeted for community- level interventions (Cotterill, 1988). From the UK, there is also a recent study of child welfare inequalities in England, Wales, Scotland and Northern Ireland that shows that structural inequalities between the four nations, differentially shape social care interventions in the lives of children and families (Bywaters et al., 2018). There is also a New South Wales (NSW) study that used post-code analysis to identify areas that generate CAN cases. As expected, the areas identified were low-income, socially disadvantaged communities (Weatherburn \& Lind, 2001).

More recently, a 2020 special edition of Children Australia contained a section that focused on Poverty and Child Abuse. An article by Ainsworth (2020) in that edition offered commentary on this issue and cited key US and British studies that pointed to the social and economic origins of child abuse and neglect. In doing so, the article noted the sparsity of Australian studies about these origins.

\section{The argument so far}

The argument so far is that the best interests of the child construct, with its focus on the rights of the child and parental pathology to protect a child, has the effect of harming a child, except in circumstances such as non-accidental injury (NAI) (Hansen \& Ainsworth, 2020). What the best interest construct has led to is an increase in the removal of children from parental care (Australian Institute of Health and Welfare [AIHW], 2021; Burns et al., 2017).

What this article proposes is a move away from this construct and, instead, a focus on the complex social determinants of CAN of which Bywaters' (2018) project on child welfare inequalities, has much to say. This is because a range of social determinants is viewed as offering a better explanation for the incidence of CAN than the best interests construct, with the result that this proposal has a preventative, not just a surveillance and detection, focus. 


\section{Substance abuse, domestic violence, and child abuse and neglect}

Both substance abuse and domestic violence are critical challenges for child protection services (Maluccio \& Ainsworth, 2009). The key issue is about the complex interaction between poverty, substance abuse and domestic violence. The National Council on Drug Abuse (NCDA) lists the following factors as common to poverty and substance abuse.

Low status and low skilled jobs, unstable family and interpersonal relationships, illegitimacy, dropping out of school, high arrest rates, high incidence of mental health disorders, poor physical health, and high mortality rates.

(National Council on Drug Abuse, 2018).

In turn, similar risk factors feature in accounts of domestic violence. They include:

[A]lcohol and drug use, previous experience of DV, pregnancy, age, separation, violence by an ex-partner, disability (intellectual or psychiatric), financial stress, employment status, income source (welfare).

(Australian Parliamentary Library, 2015).

Curiously, substance abuse is rarely mentioned in a special edition of Australian Social Work (April 2018) devoted to Child Protection and Domestic Violence, even though substance abuse is a feature of many domestic violence situations (Humphreys et al., 2018).

Given the above, there appears to be enough consensus that poverty, substance abuse and domestic violence are closely inter-twined and that, in some cases, this trio contributes significantly to the causes and consequence of CAN and other pernicious social ills.

\section{Unemployment and child abuse and neglect}

This section (and the next), of this article draw attention to the impact of unemployment and family structure on the incidence of CAN. Unfortunately, the best interests construct with the narrow focus on parental pathology obscures the way unemployment, and potentially family structure, increases the likelihood of CAN. In the US, the evidence points to the fact that children in families with "no parent in employment" are two to three times more likely to be the subject of maltreatment compared to children with employed parents (Sedlak et al., 2010. p. 11). This result is further confirmed by a recent English study of the impact of unemployment on child maltreatment (Brown \& de Cao, 2017).

Contributing to un-employability is low levels of parental education that, in turn, leads to increased family stress levels. The result is that children in lower socioeconomic status households "experienced some type of maltreatment at more than 5 times the rate of other children; they were more than 3 times as likely to be abused, and about 7 times as likely to be neglected" (Sedlak et al., 2010, p. 11). It is likely that the situation in other comparable countries is similar.

\section{Family structure and child abuse and neglect}

There is also the issue of family structure and living arrangements. It has recently been argued that non-traditional family structures (e.g., single-parent families), place children in greater danger of abuse and neglect (Sammut, 2014). This author, a historian, is known for his off-centre views about child protection and the endorsement of widespread use of adoption of children from out-of-home care, His comment about family structure is in that category (Sammut, 2015; Sammut, 2017).

Nevertheless, evidence from the US does show that compared to children "living with married biological parents, those whose single parent had a live-in partner had more than 8 times the rate of maltreatment overall, over 20 times the rate of abuse, and nearly 8 times the rate of neglect" (Sedlak et al., 2010. 
p. 12). We know that, in Australia in 20112012 , at least $32.5 \%$ of cases of substantiated abuse and neglect came from single-parent families (AIHW, 2013, Table A9). These data are not included in the AIHW report for 2017-2018 or beyond.

\section{Aboriginal circumstances}

The issues of poverty and social disadvantage have special resonance for the Australian Aboriginal community, where the construct, the best interests of the child, has been applied and has resulted in an over-representation of Aboriginal children in out-of-home care $(\mathrm{OOHC})$. Indeed, one third of all children in OOHC in NSW are Aboriginal (AIHW, 2018). This overrepresentation of Aboriginal children may be because the issues of parental poverty and community disadvantage have been largely discounted as factors in abuse and neglect cases. Colonisation and dispossession of native lands have powerfully reinforced Aboriginal poverty and disadvantage, and this continues to this day (Working with Indigenous Australians, 2021). The current allegiance to the individually focused best interest construct has resulted in far too many Aboriginal children being removed from family, community, and culture, at great cost to everyone. The Australian Bureau of Statistics (ABS) publish a socialeconomic index of areas (ABS, 2018) of advantage and disadvantage by local government areas. In NSW, the bureau nominates Brewarrina, Claymore, Lightning Ridge, Walgett, Wilcannia and Windale as the most disadvantaged post-codes. There are significant Aboriginal populations in these shires. AIHW also use the same index as the basis for a similar nomination (AIHW, 2018, p. 70).

The 2018 AIHW report further indicates that high rates of substantiation of abuse and neglect are linked to remoteness and areas of social disadvantage.

Children who were the subject of substations were more likely to be from the lowest socioeconomic areas $35 \%$ in the lowest socio-economic area compared with 7\% in the highest) (ABS, Table S12). Indigenous children who were the subject of substantiations were far more likely to be from the lowest socioeconomic areas $(45 \%)$ than non-indigenous children $(31 \%)$

(AIHW, 2018; Figures 3.5 and 3.6).

And herein lies part of the explanation as to why Indigenous children are overrepresented in the OOHC population. Data about the overrepresentation of Black and Hispanic children in the foster care system in the US tells the same story (Williams \& Offutt, 2020).

\section{Alternative interventions}

It has been argued in this article that poverty and social disadvantage are fundamental causes of the high incidence of CAN, and that the way to address this issue is not by way of interventions that are clinically focused. In this respect, the best interests of the child construct is unhelpful as far as these communities are concerned. The major child protection effort should instead be focused on prevention and be made up of community-building interventions. In fact, the focus on individual causation of CAN and its simplistic linkage to the best interests of the child with its moralistic overtones and potential explanatory bias, has obscured the social factors that may precipitate a CAN event.

This view is the result of the author's more than 10 years of Children's Court experience. This experience has included multiple conversations with parents about the impact of poverty on their child-rearing capacity. Other, similar conservations have taken place through calls by parents to the Family Inclusion Network - New South Wales (FIN -NSW) telephone information line (Ainsworth \& Berger, 2014). In addition, there is evidence that child removal by child protection authorities, as reported by Bennett et al. (2020) worsens parental circumstances 
through the loss of income and social housing and makes restoration of a child to parental care less than likely (Broadhurst \& Mason, 2020).

These proposals are, therefore, not about structural reform and the removal of social disadvantage and poverty, as desirable as this may be. Such reform is a long-term goal that would require a major anti-poverty campaign to encourage national and state government to act in relation to items such as income maintenance and social housing. An example is the Rowntree campaign (Rowntree Foundation, 2016) in England, although this is about poverty in general and is not CAN-specific. These items are beyond the traditional terrain of state child protection authorities. In addition, the long-term goal of structural reform will not aid parents who are currently accused of CAN that, for many, has its origins in social disadvantage and poverty.

My proposal is that child protection workers should work in the heart of a community, in schools and neighbourhood centres, and not in a distant town or city office. When located in high-needs communities, child protection workers can listen to parents and other community members, engage them and offer practical interventions such as budgeting, housekeeping, and parenting programmes relevant to low-income parents, as well as counselling when necessary. The focus should be on mentoring or teaching parents about how to manage their life circumstances and keep children safe (Ainsworth \& Hansen, 2018), not about surveillance as a prelude to court action. Working in this way, child protection workers can identify with the community within which they work and, in turn, put themselves in a position to build relationships with vulnerable families. Once established, these relationships provide opportunities for interventions that modify inappropriate parenting practices and make children safer. You cannot do this from a distance or via office-based counselling. Workers must be close to the families in question. The issue with the best interest construct is that it moves child protection workers away from community involvement through its focus on individual parental pathology. In that respect, it isolates potential abusive or neglectful parents from other community members who might be supportive of these parents-one consequence of which is a culture of parent blaming, shaming and stigmatisation within child protection departments (Leigh, 2017). A community-level involvement ensures that the feared "knock on the door" late in the evening by departmental caseworkers who have arrived unexpectedly to investigate a possible risk of significant harm report (ROSH) is avoided - and that is in the "best interest of the child."

\section{Protecting children is everyone's business}

This heading is taken from the Annual Report of the Council of Australian Governments for 2009-2010 in relation to the National Framework for Protecting Australia's Children (Commonwealth of Australia, 2010). If protecting Australia's children is everyone's business, then a community focused approach (rather than individualised intervention) to the detection and prevention of CAN is called for.

The social model for protecting children as outlined by Featherstone et al. (2018) who coined the phrase "the atomised child" has many of the required features. In particular, the social model seeks to replace reliance on the justice system and individualised, government-sponsored, child protection services with communitybased interventions. The argument is that persons living in local communities, and professionals, if they are embedded in these communities as suggested, will know the families that are struggling and vulnerable to the abuse and/or neglect of their children. Importantly, localised services are better able to reach out to these families, are less stigmatising, and therefore more likely to be able to engage these families in services that can prevent CAN. This is not to say that 
all families will respond to these initiatives. Some will not, and children may need to be removed from parental care. Nevertheless, this approach is likely to reduce the number of situations where removal of children from parental care, at least for a period, is necessary. An aware and vigilant local community ensures that these children are not left at risk.

In the Aboriginal community, this is illustrated by the endeavours of "Grandmothers Against Removal" (GMAR NSW). In NSW, these Aboriginal Elders (GMAR NSW, 2019) are working with the Department of Community Services to develop binding protocols to be followed in cases whenever the Department is considering the removal of children from an Aboriginal family. These protocols seek to involve the Grandmothers, as key representatives of the Aboriginal community, in the decision-making process. Before a removal decision is made, the Grandmothers ensure that community resources that might prevent removal have been fully utilised. If, the decision for removal is made (and the Elders do not oppose all removals), the Elders then make sure that the Aboriginal placement principles that are in the Care Act are observed (CYCP Act, 1988, s. 13). No child is left at risk. The social model of child protection, based on community ownership of the social issue of CAN, that is echoed in the title of this section of this article, is fully committed to maintaining the safety of children. It is also compatible with Winnicott's good enough parenting.

\section{Conclusion}

This article has raised questions about the utility of the best interests of the child construct. It has also promoted Winnicott's good enough parenting proposal as an alternative conceptualisation when CAN cases are under consideration.

In summary, there is concern about the underlying value base of the best interests construct. This construct grew out of work at Yale University and is influenced by the individualistic culture of the US. In addition, the construct is heavily influenced by Freudian theory as both Solnit and Freud were psychoanalytically trained psychotherapists. Moreover, the US culture that gave birth to the best interests construct holds parents fully responsible for CAN and largely ignores the influence of social factors, such as poverty and social disadvantage. As a result, when the best interests construct is in play, the focus in suspected cases of CAN is on individualised parental assessments and any case interventions are shaped by the belief that CAN is solely a product of parental psychopathology. In this article we have documented the influence of substance abuse, domestic violence, unemployment, and family structure on the incidence of CAN. All of which correlate with poverty and social disadvantage.

While substance abuse and domestic violence may require interventions that address parental pathology, not all CAN cases feature these issues as the dominant factors. When this is the case, individualised treatment models may serve an important purpose-but not otherwise. Finally, it is worth remembering that, between 2018 and 2019, there were 44,906 children in out-ofhome care $(\mathrm{OOHC})$ in Australia. The rate of indigenous children in care was 54 per 1,000 children, 11 times the rate for non-indigenous children where the rate was 5.2 per 1,000 children (AIHW, 2020. Figures 5.1 and 5.4). It is highly unlikely that all these children were removed from families where parental pathology was the sole precipitating factor for their placements in state care.

We need a new balance between explanations about CAN that takes account of both poverty and social disadvantage and those that have a clinical focus on parental pathology. The Featherstone et al. (2018) social model for protecting children is a move in that direction. It is for the above reasons that the best interest of the child construct warrants critical re-examination. 
A further move is that by the Anne E. Casey Foundation which, in 2020, announced a first-of-a-kind partnership between the US Children's Bureau, Casey Family Programs and Prevent Child Abuse America that aims to redesign child welfare into child and family well-being systems. This will almost certainly require a re-consideration of the best interests of the child construct and recognition of the contribution of poverty and disadvantage to child abuse and neglect. That poverty is a driving factor that shapes child welfare interventions is also highlighted in a "Protecting young children at risk of abuse and neglect" report released this year by the London based Nuffield Foundation (Nuffield Foundation, 2021).

Accepted 13 June 2021

Published 1 September 2021

\section{References}

Ainsworth, F., \& Berger, J. (2014). Family inclusive child protection practice: The history of the Family Inclusion Network and beyond. Children Australia, 39(2), 60-64.

Ainsworth, F., \& Hansen, P. (2018). Coaching parents about children's needs and navigating, the child protection and other systems. Children Australia, 43(3), 181-185.

Ainsworth, F. (2020). The social and economic origins of child abuse and neglect. Children Australia, 45(4), 202-206.

Anne E. Casey Foundation. (2020). First-of-a-kind partnership that aims to redesign child welfare into child and family well-being systems. Available at https:// www.aecf.org/blog/first-of-its-kind-partnership-aims-toredesign-child-welfare-into-child-and-family-wellbeingsystems Accessed 10 August.

Australian Bureau of Statistics. (2016). Socio-economic indexes for areas (SEIFA). Available at www//abs.gov. aubs/censushomensf/home/seifa. Accessed 10 August. ABS.

Australian Institute of Health and Welfare. (2013). Child protection Australia 2011-12. Table A9. AlHW.

Australian Institute of Health and Welfare. (2018). Children's headline indicators. No. 15, 16 and 19. Available at https://www.aihw.gov.au/reports/children-youth/ childrens-headline-indicators/contents/overview Accessed 10 August. AlHW.

Australian Institute of Health and Welfare (2020). Child protection Australia 2018-19. Child welfare series no. 72. Cat. no. CWS 74. AlHW.

Australian Institute of Health and Welfare (2021). Child protection Australia 2019-20. Trends over time for children in out-of-home care (p. vi). Child welfare series no. 74. Cat. no. CWS 78. AlHW.
Australian Parliamentary Library. (2015). Domestic violence in Australia: A quick guide to the issues. Department of Parliamentary Services.

Bennett K., Booth A., Gair S., Kibet R. \& Ros Thorpe (2020). Poverty is the problem - not parents: So tell me child protection workers, how can you help? Children Australia, 45 (4), 207-214.

Bettelheim, B. (1987). A good enough parent. Random House.

Broadhurst, K., \& Mason, C. (2020). Child removal as the gateway to further adversity: Birth mothers' account of immediate and enduring consequence of child removal. Qualitative Social Work, 19(1), 15-37.

Brown, D., \& de Cao, E. (2017). The impact of unemployment on child maltreatment in the US. Department of Economics, Discussion Paper Series No 837. University of Oxford.

Burns, K., Poso, T., \& Skivenes, M. (Eds.). (2017). Child welfare removals by the state. Oxford University Press.

Bywaters, P., Bunting, L., Davidson, G., Hanratty, J., Mason, W., McCartan, C., \& Steils, N. (2016). The relationship between poverty, child abuse and neglect: An evidence review. Joseph Rowntree Foundation.

Bywaters, P., Scourfield, J., Jones, C., Sparks, T., Elliot, M. Hooper, J., McCartan, C., Shapira, M., Bunting L., \& Daniel, B. (2018). Child welfare inequalities in the four nations of the UK. Journal of Social Work, 18(3), 1-23.

Cancian, M., Yang, M-Y, \& Slack, K. S. (2013). The effect of additional child support income on the risk of child maltreatment. Social Services Review, 87(3), 417-437.

Cocks, J. (2018, April). If a community values its children, it must cherish their parents [Paper presentation]. CFCA Webinar, Newcastle: NSW.

Commonwealth of Australia. (2010). National Framework for Protecting Australia's Children. Author.

Cotterill, A. M. (1988). The geographic distribution of child abuse in an inner-city borough. Child Abuse and Neglect, 12(4), 461-467.

Daley, D., Bachmann, M., Bachmann, B. A., Pedigo, C., Minh-Thuy, B., \& Cofffman, J. (2016). Risk terrain modelling predicts child maltreatment. Child Abuse and Neglect, 62, 29-38.

Dallek, R. (2018). Franklin D. Roosevelt. A political life. Penguin.

Doidge, J. C., Higgins, D. J., Delfabbro, P., Edwards, B., Vassallo, S., Toumbourou, J. W. \& Segal, L. (2017) Economic predictors of child maltreatment in an Australian population-based birth cohort. Child and Youth Services Review, 72, 14-25.

Dreyfus, S. N. (2020). Building a true and equitable child and family well-being system. Children's Bureau Express, 21(6), 1-2.

Eckenrode, J., Smith, E. G., McCarthy, M. E., \& Dineen, M. (2014). Income inequality and child maltreatment in the United States. Paediatrics, 133; 454-461.

Everson N. (2016a). Special Broadcasting Service. Cultural atlas. Available at https://culturalatlas.sbs.com.au/uk Accessed 10 August.

Everson N. (2016b). Special Broadcasting Service. Cultural atlas. Available at https://culturalatlas.sbs.com.au/us Accessed 10 August. 
Family Functional Therapy - Child Welfare (FFT-CW) ${ }^{\circledR}$. Family Functional Therapy - Child Welfare. Available at https://fftllc.com/fft-childwelfare Accessed 10 August.

Featherstone, B., Gupta, A., Morris, K., \& White, S. (2018), Protecting children. A social model. Policy Press.

Forbes N, (2019). Special Broadcasting Service. Cultural atlas. Available at https://culturalatlas.sbs.com.au/newzealand Accessed 10 August.

Ghate, D., \& Hazel, N. (2002). Parenting in poor environments. Stress, support, and coping. Jessica Kingsley.

Goldstein, L., Freud, A., \& Solnit, A. J. (1973). Beyond the best interests of the child. Free Press.

Goldstein, L., Freud, A., Burlingham, D., \& Solnit, A. J. (1979). Before the best interest of the child. Free Press.

Goldstein, J., Freud, A., Solnit A. J., \& Goldstein, S. (1986). In the best interest of the child. Free Press.

Goldstein, J., Solnit, A. J., Goldstein, S. (with Freud, A.). (1996). The best interest of the child. The least detrimental alternative. Free Press.

Government of Hong Kong (2013). Epidemiology of child abuse and its geographic distribution in Hong Kong: An important social indicator of different districts and communities, Available at Epidemiology of Child Abuse and Its Geographic Distribution in Hong Kong: (pico.gov. hk) Accessed 10 August.

Grandmothers Against Removal NSW. (2019). Media release. Available at https://www.facs.nsw.gov.au/sear ch? $\mathrm{q}=$ grandmothers+against+removal+nsw Accessed 10 August.

Guggenheim, M. (2005). What's wrong with children's rights. Harvard University Press.

Hansen, P., \& Ainsworth, F. (2009). The "best interests of the child" thesis: Some thoughts from Australia. International Journal of Social Welfare, 18, 431-439.

Hansen, P., \& Ainsworth, F. (2011). In 'the best interests of the child': Critical reflections on an overused construct. Children Australia, 36(1), 12-17. https://doi.org/10.1375/ jcas.36.1.12

Hansen, P., \& Ainsworth, F. (2020). Examining child protection practice in New South Wales: Non-accidental injury and the principle of strict liability. Children Australia, 45(1), 8-13.

Humphreys C., Healy L., Kirkwood D. \& Nicholson D. (2018) Children living with domestic violence: A differential response through multi-agency collaboration. Australian Social Work, 71 (2), 162-174.

Institute for Research on Poverty. (2017). Fast Focus. Research/Policy brief no. 27. Financial causes and consequences of child maltreatment. University of Wisconsin-Madison.

Joseph Rowntree Foundation. (2016). The relationship between poverty, child abuse and neglect: An evidence review.

Kahneman, D. (2011). Thinking, fast and slow. Farrar, Strauss and Giroux.

Krumer-Nevo, M. (2020). Radical hope. Poverty-aware practice for social work. Policy Press.
Leigh, J. (2017). Blame, culture and child protection. Palgrave Macmillan.

Maluccio, A. N., \& Ainsworth, F. (2009). Drug use by parents: A challenge for family reunification practice. In $\mathrm{M}$. Courtney \& J. Thoburn (Eds.), Children in state care. The Library of Essays in Child Welfare and Development series. Routledge.

Multi-systemic Therapy - Child Abuse and Neglect (MSTCAN ${ }^{\circledR}$. Multi-systemic therapy. Available at www/ozchild. org.au/mst-can/ Accessed 10 August.

National Council on Drug Abuse. (2018). Drug talk. NCDA.

Nuffield Foundation. (2021). Protecting young children at risk of abuse and neglect. Nuffield Foundation.

Saar-Heiman, Y., \& Gupta, A. (2019). The poverty-aware paradigm for child protection: A critical framework for policy and practice. British Journal of Social Work, 50(4), 1167-1184.

Sammut, J. (2014, January 30). Abuse a bigger danger in non-traditional families. The Australian, p. 10.

Sammut, J. (2015). The madness of Australian child protection. Why adoption will rescue Australia's underclass of children. Children Australia, 41(2), 162-163.

Sammut, J. (2017). Resetting the pendulum: Balanced, effective, accountable child protection systems and adoption reform in Australia. Children Australia, 43(3), 217-219.

Sedlak, A. J., Mettenburg, J., Basena, M., Petta, I., McPherson, K., Greene A., \& Li S. (2010). Fourth National Incidence Study of Child Abuse and Neglect (NIS-4): Report to Congress. U.S. Department of Health and Human Services, Administration for Children and Families.

Spinak, J. (2007). When did lawyers for children stop reading Goldstein, Freud and Solnit? Lessons from the twentieth century on best interests and the role of the child advocate. Family Law Quarterly, 42(2), 393-411.

Weatherburn, D., \& Lind, B. (2001). Delinquency-prone communities. Cambridge University Press.

Williams, C., \& Offutt, K. (2020). Black children are overrepresented in the foster care system: What should we do about it? Children's Bureau Express, 21(6), 1-2.

Winnicott, D. W. (1960). The theory of the parent-infant relationship. International Journal of Psychoanalysis, 41, 585-595.

Winnicott, D. W. (1973). The child, the family, and the outside world. Penguin.

Working with Indigenous Australians. (2021). Available at www.workingwithindigenous australians.info/content/ History-3colonisation/html Accessed 10 August.

\section{Statutes}

NSW Children and Young Persons (Care and Protection) Act, 1998

Patient Protection and Affordable Care Act, 2010. PL 111148. 